\title{
SEGURIDAD DE LOS DOCUMENTOS DE ARCHIVO: ESTUDIO DE CASO DEL ARCHIVO DEL AYUNTAMIENTO DE BARCELONA
}

\author{
Olga Giralt, Carme Vidal-Pijoan y Carlos Pérez-Soler
}
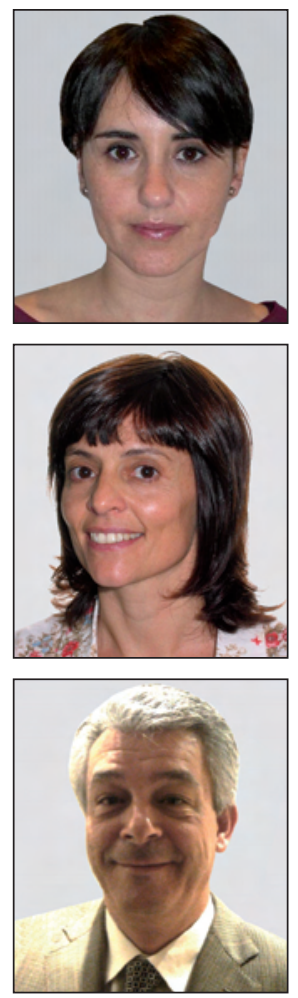

Carlos Pérez-Soler, con más de 25 años en el sector de las TICs, se ha especializado en infraestructuras de almacenamiento. Empleado fundador de Hitachi Data Systems (HDS) en España, en la actualidad es su director para la zona noreste, donde la empresa ha alcanzado la mayor penetración de mercado en venta de sistemas de almacenamiento.

Olga Giralt es licenciada en filología hispánica y en documentación por la Universitat de Barcelona. Desde 2008 es responsable del área de consultoría de Doc6. Ha participado y coordinado distintos proyectos de implementación de sistemas de gestión documental.

Doc6. Consultores en recursos de información http://www.doc6.es ogiralt@doc6.es

Carme Vidal-Pijoan es licenciada en geografía e historia con especialidad en antropología cultural por la Universitat de Barcelona y ha cursado el graduado superior en archivística y gestión de documentos en la Universitat Autònoma de Barcelona. Ha desarrollado su labor profesional en diversos archivos. Desde 2010 trabaja en el área de consultoría de Doc6.

cvidal@doc6.es

\section{Resumen}

El crecimiento exponencial de los contenidos digitales en las organizaciones y la obligación de asegurar la preservación de la documentación hace más evidente la necesidad de disponer de mecanismos que garanticen la autenticidad, integridad y seguridad de la misma. Se presenta el caso del Archivo del Ayuntamiento de Barcelona que, a partir de la experiencia pionera del Archivo del Ayuntamiento de Amsterdam, está implementando el sistema Hitachi Content Platform (HCP) de Hitachi Data Sytems como repositorio de los documentos digitales. El proyecto comprende también una revisión de las pautas de trabajo actuales con el fin de establecer procedimientos y buenas prácticas de digitalización.

\section{Palabras clave}

Digitalización, Documentos digitales, Preservación, Archivos, Hitachi Data Systems, Ayuntamiento de Barcelona, España

\section{Title: Records security: case study of the Barcelona City Council Archive}

\begin{abstract}
The exponential growth of digital content in organizations and the obligation to ensure the preservation of documents makes the need more evident for mechanisms to ensure its authenticity, integrity and security. A case of the Archives of the Barcelona Town Hall, following the pioneering experience of the Amsterdam Town Hall Archives, is presented. The Hitachi Content Platform (HCP) from Hitachi Data Systems was installed as a secure repository of digital documents. The project also included a review of current working patterns in an effort to establish procedures and best practices for digitization.
\end{abstract}

\section{Keywords}

Digitization, Digital Documents, Preservation, Archives, Hitachi Data Systems, Barcelona City Council, Spain. 
Giralt, Olga; Vidal-Pijoan, Carme; Pérez-Soler, Carlos. "Seguridad de los documentos de archivo: estudio de caso del Archivo del Ayuntamiento de Barcelona". El profesional de la información, 2011, marzo-abril, v. 20, n. 2, pp. $202-205$.

\section{Introducción}

A medida que crecen exponencialmente los contenidos digitales -un $60 \%$ más cada año ${ }^{1}$ - se hace más evidente la necesidad de garantizar su autenticidad e integridad pensando sobre todo en su acceso y disponibilidad en el futuro.

Un estudio de la Storage Networking Industry Association (SNIA) $)^{2}$ revela que a pesar de que un $68 \%$ de los datos dejan de consultarse a partir de los 90 días de su creación, la legislación o las normativas obligan a guardarlos por períodos más largos de tiempo, lo cual a veces comporta una gran complejidad en cuanto a su administración y mantenimiento (copias de seguridad, etc.).

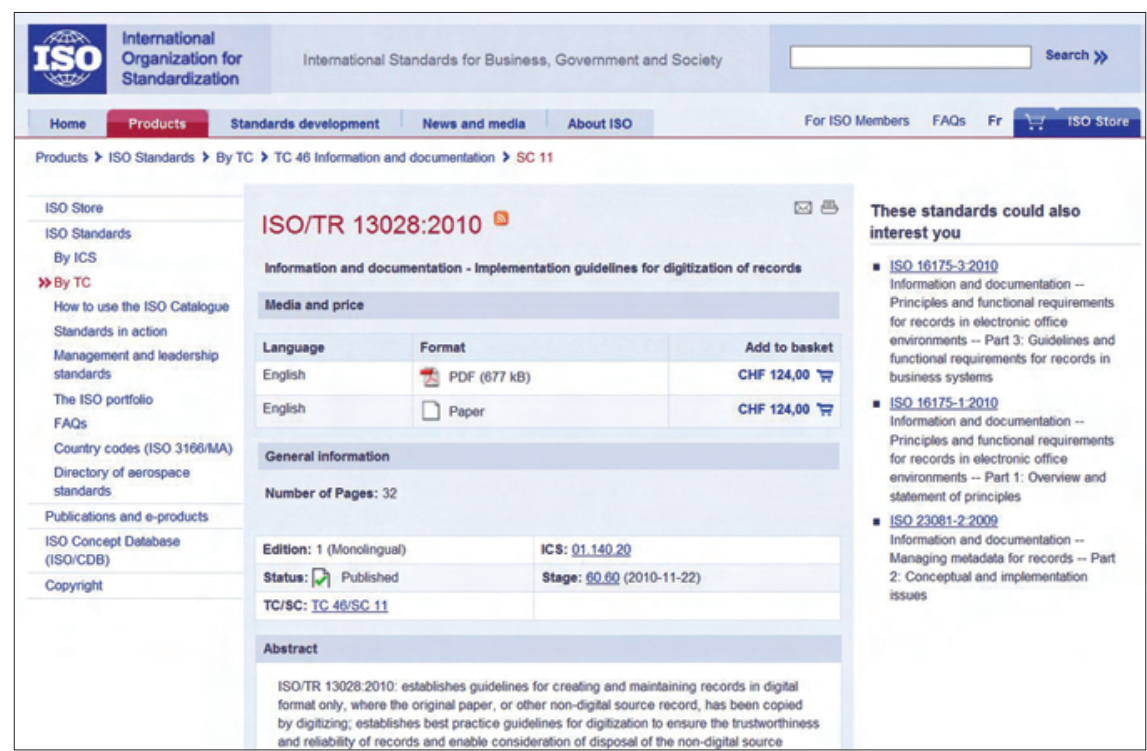

http://www.iso.org/iso/catalogue_detail
En concreto, SNIA ha identificado los siguientes aspectos relacionados con la seguridad de la información:

- Confidencialidad: sólo acceden las personas autorizadas.

- Integridad: permanece completa y en su forma original.

- Disponibilidad: puede usarse según unos determinados parámetros operacionales.

- Posesión: está bajo custodia de personal autorizado.

- Autenticidad: se ajusta a la realidad, es la original, no se representa como algo que no es.

- Utilidad: se adecua a una finalidad y es usable.

- Privacidad: está protegida contra intrusos.

- Uso autorizado: sólo está disponible para personal autorizado.

- No repudio: la persona que la ha generado no puede negar su acción en un futuro.

Cuando se realiza un proyecto de digitalización no sólo hay que prever el espacio de almacenamiento de los datos sino también su preservación de manera segura

En definitiva, cuando se realiza un proyecto de digitalización no sólo hay que prever el espacio de almacenamiento de los datos sino también su preservación de manera segura, mediante sistemas que garanticen que será posible recuperarla en cualquier momento. Si es preciso habrá que poder acceder y visualizar los documentos en la misma forma en que se crearon, a pesar de la obsolescencia tecnológica de soportes y formatos, pudiendo confiar siempre en su fiabilidad. Y todo ello con la máxima eficiencia y los mínimos costes de ejecución y mantenimiento futuros.
Está claro que semejantes retos no están al alcance de cualquier tipo de sistema de almacenamiento ni de cualquier tipo de organización. Los tradicionales son hoy insuficientes y se hace necesario disponer de otros que garanticen la seguridad de la documentación y que permitan recuperarla. Además el sistema usado debe tener en cuenta tanto los documentos originarios en papel que han pasado un proceso de digitalización como los originalmente digitales.

Para orientar la digitalización de archivos, en noviembre de 2010 apareció la norma ISO/TR 13028 Information and documentation - Implementation guidelines for digitization of records $s^{3}$, que ofrece un marco de buenas prácticas para planificar proyectos de digitalización responsables y que garanticen los mejores resultados. Hay que resaltar las recomendaciones sobre la captura y gestión de los metadatos asociados a las imágenes digitales que permitan su indización y explotación en otros contextos diferentes al de su creación. Propone que si es apropiado se amplíen las posibilidades de difusión de las imágenes y de su contenido.

El siguiente paso es escoger la mejor opción de almacenamiento seguro.

\section{Archivo del Ayuntamiento de Amsterdam}

En 2010 el Stadsarchief Amsterdam ${ }^{4}$, uno de los mayores del mundo con unos 35 kilómetros de estanterías y con más de 8 millones de documentos digitales públicos y de empresas, se planteó abordar el tema de la seguridad y de encontrar una solución escalable para asegurar la longevidad de los documentos digitalizados.

Fue elegido HCP de Hitachi Data Sytems, un sistema de archivo CAS (content adressable storage) de almacenamien- 
to inteligente tipo worms (write once read many) que permite consultar la información las veces que sea necesario garantizando que los documentos no sufrirán ninguna alteración por parte de los usuarios. Además su escalabilidad da respuesta a los requerimientos presentes y seguramente futuros.

Otras características del sistema $H C P$ son:

- Facilidad de integración con otras aplicaciones gracias al uso de protocolos estándar: NFS, CIFS/SMB, HTTP, SMTP, WebDav.

- Ingesta de contenidos y metadatos.

- Indexación y búsquedas en metadatos y texto completo. Recuperación independiente del tipo o formato de los documentos.

- Creación de políticas de retención

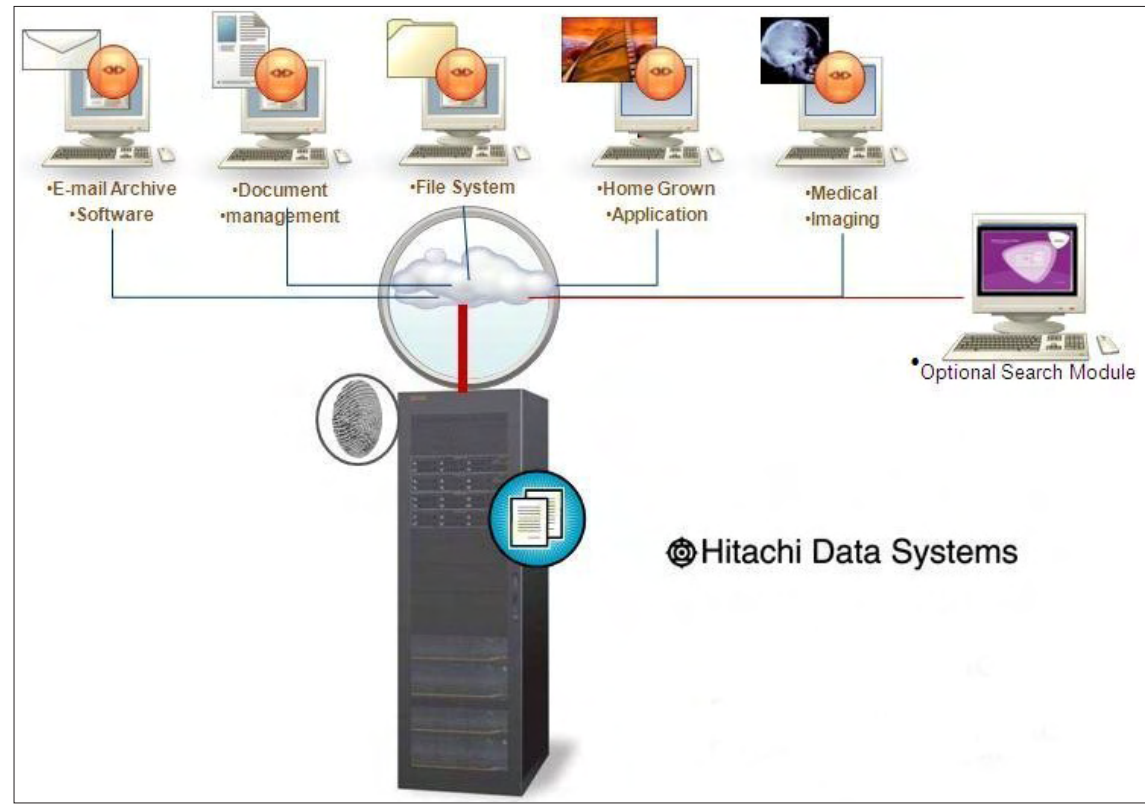

Hitachi Data Systems auto administradas.

- Chequeo continuo de la integridad de los datos, replicación, encriptación, deduplicación y auditoría de acceso.

Según Bert Nijhoff, director del Archivo de Amsterdam, una vez concretadas las políticas y pautas corporativas de gestión de los documentos de archivo, la tecnología pasa a jugar un papel muy importante. Se necesitan mecanismos de control que permitan garantizar permanentemente la autenticidad de los documentos, atendiendo a la legislación de Holanda en el caso de Amsterdam. A cada objeto digital se le adjudica un código y el sistema valida que no ha habido ningún cambio. Asimismo facilita información sobre la aplicación de políticas de disposición de los documentos, indicando si es necesario mantenerlos o destruirlos en aplicación de la legislación vigente.

Fue también importante poder enlazar el archivo con el sistema de gestión de metadatos (en este caso ScopeArchiv), y el hecho de usar estándares abiertos posibilita la integración futura en otros sistemas si fuera necesario.

Por otra parte, para una mayor seguridad (contingencia frente a un desastre) se instaló un segundo sistema HCP que era una réplica exacta del primero, estando ambos permanentemente sincronizados. El proyecto se inició con una capacidad de 18 TB, y el sistema actual puede ampliarse hasta 247 PB.

El proyecto ha simplificado la manera en que se realizaban muchas tareas al disponer de una única interfaz de gestión de objetos digitales en el entorno de la intranet, que almacena también la información relevante asociada -metadatos de descripción, preservación, etc.

La experiencia del archivo de la ciudad de Amsterdam demuestra que los principales problemas se han debido al cambio del papel a digital, pues en el "background" histórico de los archivos públicos el papel ha tenido -y tiene- un rol predominante. La necesaria implicación de todo el personal conlleva la adquisición de nuevos conocimientos y habilidades.

Por otra parte, los objetos digitales están evolucionando muy rápidamente y no siempre en la misma dirección por lo que al inicio del proyecto fue necesario redefinir las pautas existentes.

\section{Archivo del Ayuntamiento de Barcelona}

La experiencia pionera del archivo de Amsterdam llegó al Archivo del Ayuntamiento de Barcelona ${ }^{5}$, que es el primero en España en implementar una solución de este tipo.

Se empezó realizando un análisis de situación para adecuarla a las nuevas necesidades. Durante años, en los diferentes centros del Sistema Municipal de Archivos del Ayuntamiento de Barcelona se habían impulsado proyectos de digitalización de sus fondos con el objetivo de ampliar su difusión y asegurar la preservación de los documentos originales, facilitando la consulta en sala de las copias digitales de documentos cuyos soportes originales eran frágiles o sufrían alguna patología.

En la medida en que estos proyectos de digitalización iban aumentando se empezó a evidenciar la complejidad de gestionar el almacenamiento en los varios soportes habituales de trabajo (CD, DVD o HDD), así como la saturación de los espacios reservados en las carpetas de la red institucional. Desde el principio se detectó sin embargo que la solución no pasaba por un simple aumento de la capacidad de almacenaje, sino que era necesario diseñar un proyecto de mayor alcance. Éste fue impulsado por Joaquim Borràs, archiverojefe, con un equipo de archiveros e informáticos, y se inició en julio de 2010 con un triple objetivo:

- Establecer una política y unos procedimientos de digitalización comunes para todos los centros del Sistema Municipal de Archivos.

- Implementar un sistema que diera respuesta a las necesidades de almacenaje de la documentación digitalizada en los diferentes centros de archivo y que garantizara su seguridad y su preservación.

- Diseñar un sistema de acceso y consulta en línea al patrimonio documental digitalizado que permitiera dar más 
difusión a los fondos y colecciones a través del propio aplicativo de archivo con sus herramientas renovadas de búsqueda y con un canal web de consulta.

Se seleccionó también HCP como repositorio seguro integrado en el sistema actual de gestión de la documentación de archivo.

Por otra parte, dentro del marco del proyecto se ha realizado además un trabajo de consultoría para conocer con detalle las formas de trabajo y las necesidades de los diferentes centros de archivo.

El establecimiento de las políticas de digitalización se ha concretado en la elaboración de un manual o protocolo corporativo que establece las pautas de trabajo para garantizar productos digitales de calidad, que se ajusten a los objetivos previstos y que aporten el mayor rendimiento. Este protocolo se plantea como un documento abierto a las modificaciones necesarias para adaptarse a la legislación, los nuevos usos o la tecnología futura.

El trabajo en equipo de archiveros, informáticos, gestores, etc., fue clave en el avance del proyecto

La previsión es terminar el proyecto en marzo de 2011, tanto en lo que concierne a su acceso a través de la intranet, como en entorno web. En el momento de realización de este artículo el proyecto está en una fase muy avanzada y como primeras "lecciones aprendidas" se puede señalar que:

- La parte de análisis, con un trabajo de campo en los distintos centros y previa a la implementación tecnológica, ha contribuido a tener unas líneas de actuación corporativas claras.

- El trabajo en equipo: archiveros, informáticos, gestores, etc., ha sido un aspecto clave en el avance del proyecto.

- Obviamente, hay que dimensionar el crecimiento de información para planificar el volumen de los sistemas de almacenamiento.

- Las pautas de trabajo consensuadas garantizarán la calidad de los proyectos de digitalización.

Es importante resaltar la necesidad de buscar políticas comunes de digitalización y descripción de registros en los diferentes archivos aun a pesar de la variedad de contextos en los que cada uno trabaja. Dentro de los objetivos estratégicos del proyecto se encuentra la optimización de los recursos dedicados a la digitalización para asegurar su sostenibilidad en el futuro.

La difusión de la información a través de la web corporativa, ofreciéndola al público en general, abre muchas expectativas: el archivo es mucho más conocido y consultado, por lo que se optimiza el trabajo realizado, y se produce un acercamiento de los usuarios que es muy positivo para ambas partes.

\section{Referencias}

1. "Data, data everywhere". The economist, 27 feb. 2010. http://www.economist.com/node/15557443

2. http://www.snia.org/home/

3. http://www.iso.org/iso/catalogue_detail.htm?csnum ber $=52391$

4. http://cwhonors.org/viewCaseStudy2010.asp?Nominati on $I D=227 \&$ Username $=a c a$

5. http://www.bcn.cat/arxiu

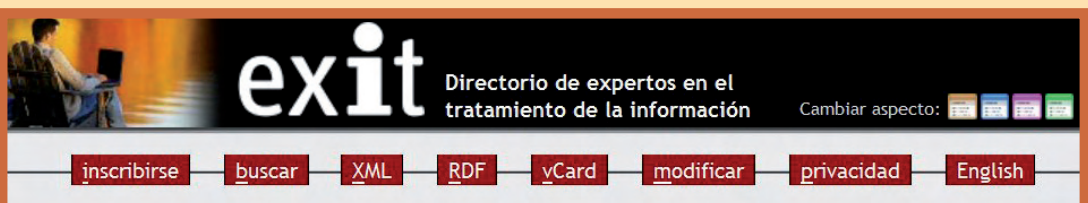

sidro F. Aguillo Caño

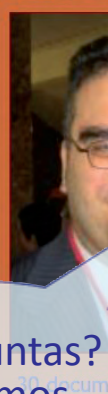

Exit ID: 67

ResearcherID: A-7280-2008

IraLIS: Aguillo, Isidro F. ¿Qué es?

Institución: Consejo Superior de Investigaciones Científicas (CSIC)

Centro de Ciencias Humanas y Sociales (CCHS) Laboratorio de Cibermetría

Dirección: Albasanz, 26-28

Código postal: 28037

Ciudad: Madrid

Provincia: Madrid

País: ES - España

Teléfono: $+34-916022890$

Fax: +34-916 022971

Correo-e: isidro.aguillo @cchs.csic.es

Ya somos más de 2.000
Web institucional: http://www.cchs.csic.es Pagerank $\square \mathbf{8 / 1 0} 88$ popularidad
Para titulados con más de

1 año de experiencia, que hayan publicado algún artículo o ponencia o puedan dar clase más de 1 hora. 